\title{
FLAMMABILITY TESTS ON HOT SURFACE FOR CASTOR OIL
}

\author{
ŞOLEA Liviu Cătălin, DELEANU Lorena \\ "Dunarea de Jos" University, Faculty of Engineering, Galati, Romania \\ corresponding authors: csolea@ugal.ro
}

\begin{abstract}
For this paper, the authors studied the behavior of castor oil, when it accidentally reaches a hot surface. Thus, the lowest temperature at which castor oil ignited at least once in three tests and the highest temperature at which castor oil did not ignite in three tests were determined. To determine as accurately as possible these two temperatures, a total of 29 tests were performed. The procedure complies with ISO 20823:2018 Petroleum and related products -Determination of the flammability characteristics of fluids in contact with hot surfaces - Manifold ignition test.
\end{abstract}

Keywords: Castor oil, flammability test, hot surface, ecological fluids

\section{INTRODUCTION}

In the last 20 years, due to the strong industrialization, there is an increasing emphasis on environmental protection and the widespread use of environmentally friendly materials. One of the research directions is the replacement of technical minerals and synthetic fluids with fluids obtained from biodegradable vegetal oils. In order to be able to use such fluids obtained from vegetal oils, they must meet a number of physical properties, such as: high viscosity, high pressure resistance, high stability to oxidation, anti-wear properties, flammability at high temperature, etc.

The most important vegetal oils analyzed by researchers [1] - [9] are: rapeseed oil, soybean oil, olive oil, palm oil, sunflower oil, corn oil, castor oil.

During the operation of industrial equipment, accidents may occur, in which various technical, flammable fluids can reach hot surfaces causing the ignition of fluids leading to significant damage. In order to avoid such undesirable incidents, when designing equipment using lubricants, hydraulic oils, material processing fluids, the ignition temperature of fluids on hot surfaces must be taken in to account.

Castor oil is a vegetal oil obtained by pressing the seeds of the plant called castor oil (Ricinus Communis). Castor oil is a nonedible oil, so it is used mainly in the chemical and pharmaceutical industry to obtain: soaps, paints, coatings, inks, lubricants and various drugs. The largest producers of castor oil are located in India, China and South America.

Castor bean oil has a content of $90 \%$ ricinoleic acid, $4 \%$ linoleic acid, 3\% oleic acid, $1 \%$ stearic acid and $1 \%$ linolenic acid [2]. Castor oil is the most important source of hydroxylated fatty acids used in the chemical industry [2]. Ricinoleic acid, present in high concentration in castor oil, provides oxidative stability to the oil and a relatively long shelf life compared to other oils by preventing the formation of peroxide [3]. Berman and others [4] studying castor oil, observed that methyl esters of castor oil can be used as a source of biodiesel mixed with diesel, but it was found that the very high concentration of ricinoleic acid directly affects the kinematic viscosity and temperature of biodiesel refining. Thus, the degree of mixing of methyl esters in diesel cannot exceed $10 \%$ [4].

Bongfa and others [8] observed a superior tribological behavior of castor oil as compared to a 20W50 synthetic engine oil. Adequately additived castor oil could be an important alternative in replacing mineral and synthetic oils with environmentally friendly lubricants, based on vegetal oils.

An important technical characteristic of lubricants is the flammability on hot surfaces. Flammability temperature is the lowest temperature at which a fluid catches fire.

In this paper, the authors determined the lowest temperature at which castor oil ignites and also the highest temperature at which castor oil does not ignite on a heated surface.

\section{EQUIPMENT AND PROCEDURE}

The tests were performed on the installation in Figure 1 and it consists of: 1 - graduated oil container, 2 - switch on/off, 3 - valve for adjusting oil flow, 4 - metallic box, 5 - tray for collecting the oil, 6 - heated cylindrical manifold, 7 - oil pipe. 
The installation simulates a probable oil leak on a heated surface, thus a quantity of $10 \mathrm{ml} \pm 0.5 \mathrm{ml}$ is dropped for $50 \pm 5$ seconds on a heated cylinder at the test temperature. The cylinder temperature remains constant throughout the test.

A crude castor oil supplied by Humanity Aruhaz KFT was used for the tests.

The dripping system is a gravitational system, composed of the following components: graduated oil container, switch on/off, valve for adjusting oil flow, oil pipe (Fig. 1).

All tests were performed so that the oil droplets came into contact with the middle of the cylinder. After each test, the cylinder is cooled to $30{ }^{\circ} \mathrm{C}$ or room temeprature and then cleaned to remove any traces of burnt oil.

The tests were recorded with a video camera and then the important sequences were selected for the analysis of the oil behavior on hot surface.

The precision temperature measured by a high quality thermocouple, attached to the teated manifold was of $\pm 5^{\circ} \mathrm{C}$. The authors applied the method of interval halving until the temperature at which the fluid does not burn in any of the three tests performed. The tests were stopped when the difference between these temperatures was of 5 ${ }^{\circ} \mathrm{C} . . .10^{\circ} \mathrm{C}$.

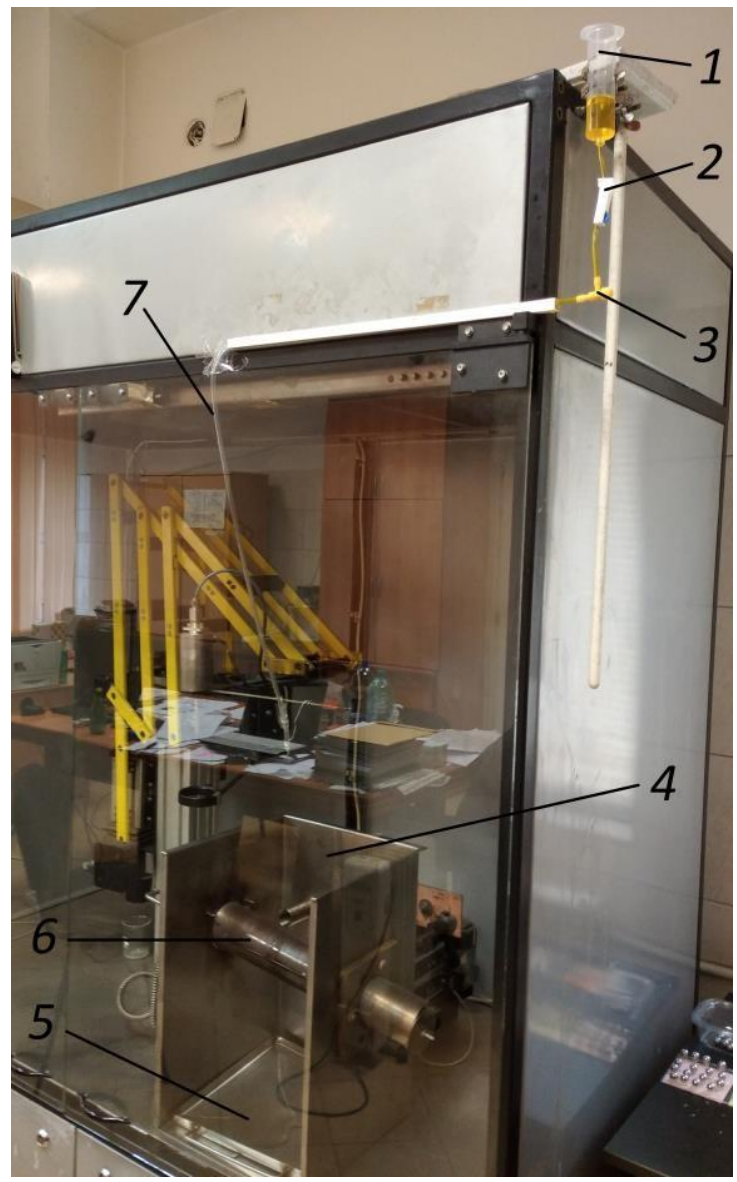

Fig. 1. The equipment for testing the fluid flammability on hot surface

\section{EXPERIMENTAL RESULTS}

Knowing the flash point temperature of $284{ }^{\circ} \mathrm{C}$ for castor oil [1], it was chosen that the first test temperature should be $300{ }^{\circ} \mathrm{C}$, at this temperature the oil did not ignite. The test temperature was then raised by $100{ }^{\circ} \mathrm{C}$ to $400{ }^{\circ} \mathrm{C}$ and even at this temperature the oil did not ignite. At $500{ }^{\circ} \mathrm{C}$, the oil does not ignite during the test period $(55 \mathrm{~s})$. But 7 seconds after the test is over, the oil remaining on the heated cylinder ignites and burns for 6 seconds (Fig. 2a). Due to this, it is possible to obtain a flammability temperature above the temperature of $500{ }^{\circ} \mathrm{C}$.

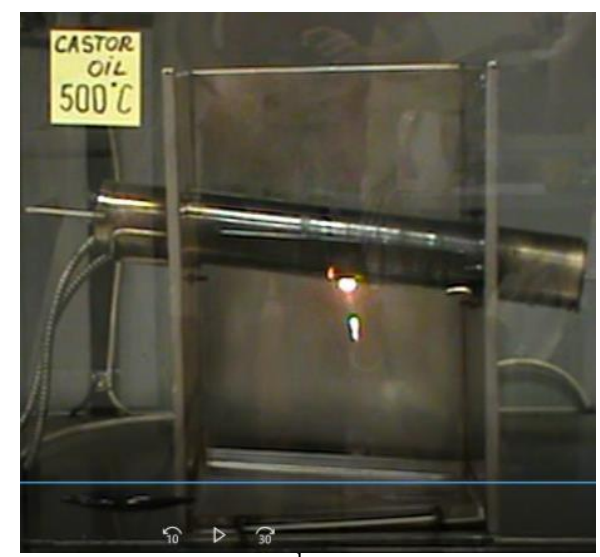

a) $62^{\text {nd }}$ second

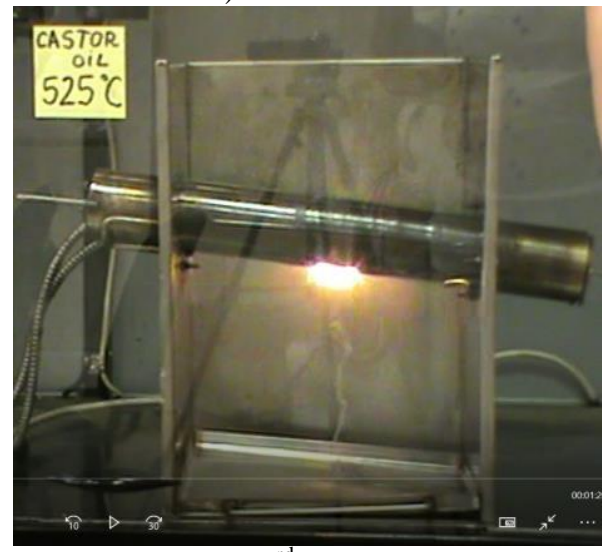

b) $3^{\text {rd }}$ second

Fig. 2. Castor oil tested at $500{ }^{\circ} \mathrm{C}$ (a) and $525^{\circ} \mathrm{C}$ (b)

The next test was performed at a temperature of $525{ }^{\circ} \mathrm{C}$ and, at this temperature, the oil ignites very quickly (in 3rd second) (Fig. 2b) and it burns throughout the test. The temperature of $525{ }^{\circ} \mathrm{C}$ is considered to be a first minimum temperature at which the flammability on hot surface of castor oil takes place, above this temperature any performed test would establish that castor oil is inflamed.

Next, an ignition temperature of half the range $500{ }^{\circ} \mathrm{C}-525{ }^{\circ} \mathrm{C}$ is sought, the temperature of $512{ }^{\circ} \mathrm{C}$ was chosen. In the case of testing at $512{ }^{\circ} \mathrm{C}$, the oil reaches the flammable temperature very quickly (after 3 seconds) (Fig. 3a). 


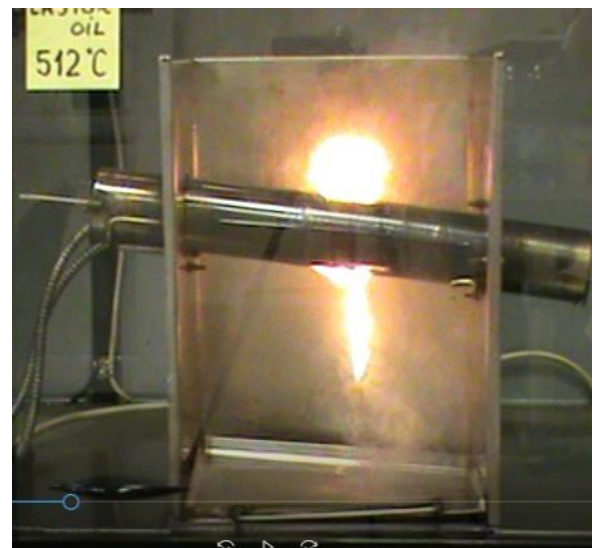

a) $3^{\text {rd }}$ second

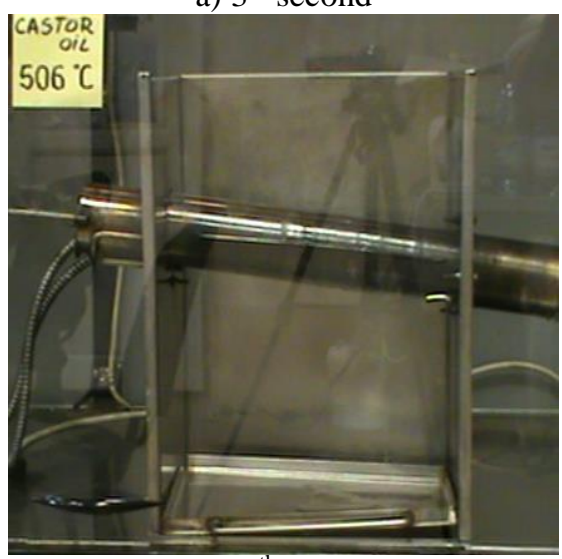

b) $55^{\text {th }}$ second

Fig. 3. Castor oil tested at $512{ }^{\circ} \mathrm{C}$ (a) and $506^{\circ} \mathrm{C}$ (b)

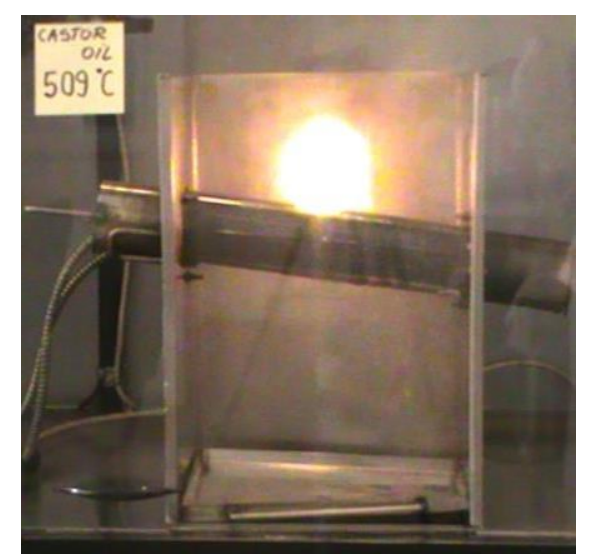

a) $43^{\text {rd }}$ second

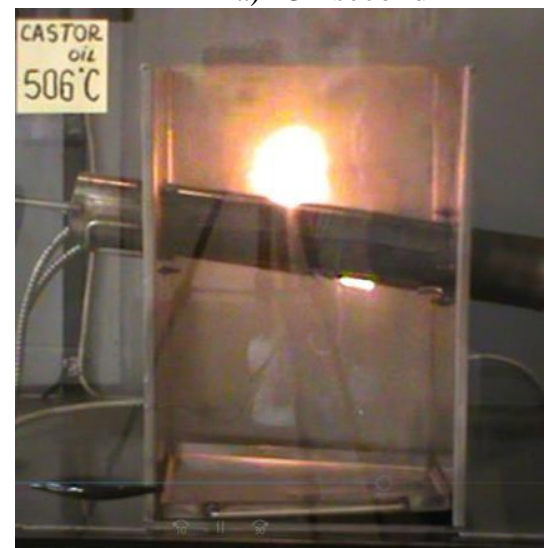

b) $44^{\text {th }}$ second

Fig. 4. Castor oil tested at $509^{\circ} \mathrm{C}$ ( a) and $506{ }^{\circ} \mathrm{C}($ (b)
The test temperature is getting lower and a temperature halfway between $500{ }^{\circ} \mathrm{C}-512{ }^{\circ} \mathrm{C}$ is chosen. The following test was performed at $506^{\circ} \mathrm{C}$, temperature at which the oil did not ignite (Fig. 3b). The test temperature is increased and the temperature of $509^{\circ} \mathrm{C}$ is chosen. In the case of the test carried out at $509{ }^{\circ} \mathrm{C}$, the oil ignites towards the end of the test period, i.e. in 43th second (Fig. 4a). It is returned with a new test at $506{ }^{\circ} \mathrm{C}$, this time the oil ignites but it ignites late, after 44 seconds (Fig. 4b).

The temperature is getting lower and a test temperature in the middle of the range $500{ }^{\circ} \mathrm{C}-506$ ${ }^{\circ} \mathrm{C}$, which is $503{ }^{\circ} \mathrm{C}$, is chosen. At this temperature the oil ignites relatively quickly after 10 seconds (Fig. 5a). Return to the test temperature of $500{ }^{\circ} \mathrm{C}$. At this temperature it was previously found (Fig. 2a) that the oil does not ignite during the test period (55 s) but which ignites after 7 seconds from the end of the test.

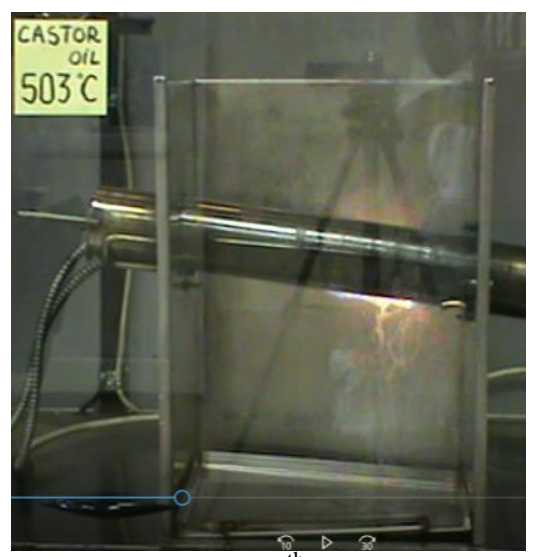

a) $10^{\text {th }}$ second

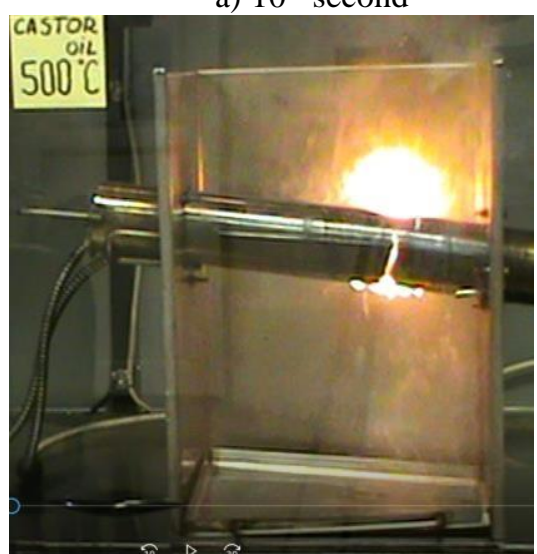

b) $12^{\text {nd }}$ second

Fig. 5. Castor oil tested at $503{ }^{\circ} \mathrm{C}$ (a) and $500{ }^{\circ} \mathrm{C}$ (b)

In order to establish that this temperature (500 ${ }^{\circ} \mathrm{C}$ ) is the one at which the oil does not ignite, four tests were performed. After the first three tests, the oil does not ignite (neither during the test period nor after it) but ignites on the fourth test.

In this last test, the ignition occurs relatively quickly, after 12 seconds (Fig. 5 b).

Then the temperature is getting lower by $5{ }^{\circ} \mathrm{C}$ (to $495{ }^{\circ} \mathrm{C}$ ), the temperature at which two tests were performed. 


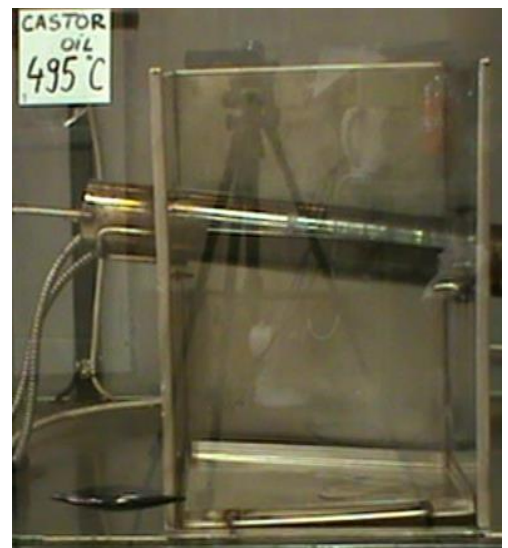

a) $55^{\text {th }}$ second

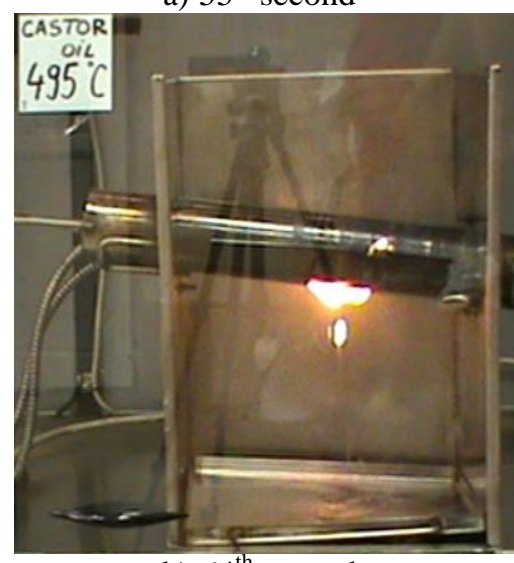

b) $64^{\text {th }}$ second

Fig. 6. Castor oil tested at $495^{\circ} \mathrm{C}$

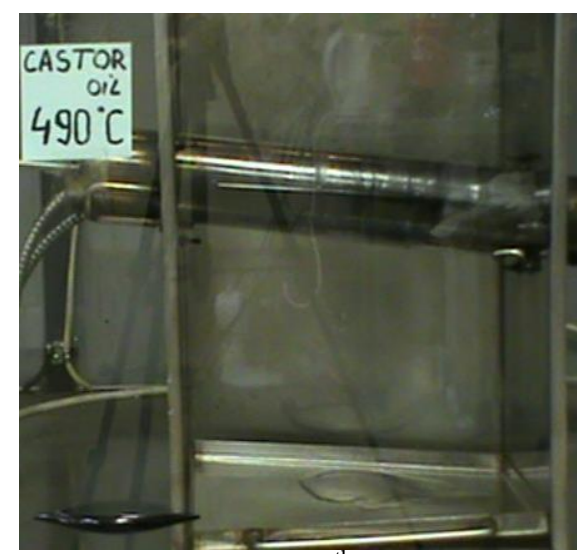

a) Test $1\left(55^{\text {th }}\right.$ second $)$

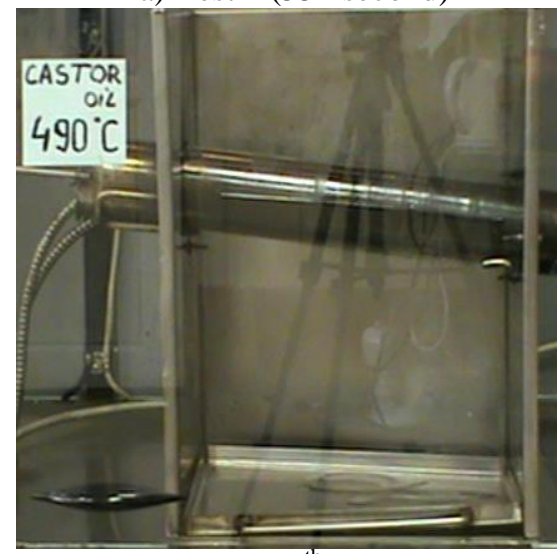

b) Test $6\left(55^{\text {th }}\right.$ second $)$

Fig. 7. Castor oil tested at $490{ }^{\circ} \mathrm{C}$
At the first test, it is observed that the oil does not ignite during the whole test period, but at the contact of the oil with the heated surface of the cylinder a lot of smoke is emitted. In the second test, it is noticed that the oil does not ignite during the test period (Fig. 6a), but 9 seconds after the test has ended, the oil remaining on the heated cylinder ignites and burns for 11 seconds (Fig. 6b).

The temperature of $495{ }^{\circ} \mathrm{C}$ was considered to be a probable oil ignition temperature, so the test temperature was lowered by $5^{\circ} \mathrm{C}$, to $490{ }^{\circ} \mathrm{C}$.

At a temperature of $490{ }^{\circ} \mathrm{C}$, for a good accuracy of the result, six tests were performed, in all six tests the oil did not ignite during the test period or after. In figure 7 exemplified two of the six tests performed.

To check the minimum ignition temperature of the oil, the temperature was returned to $495{ }^{\circ} \mathrm{C}$ and five tests were performed.

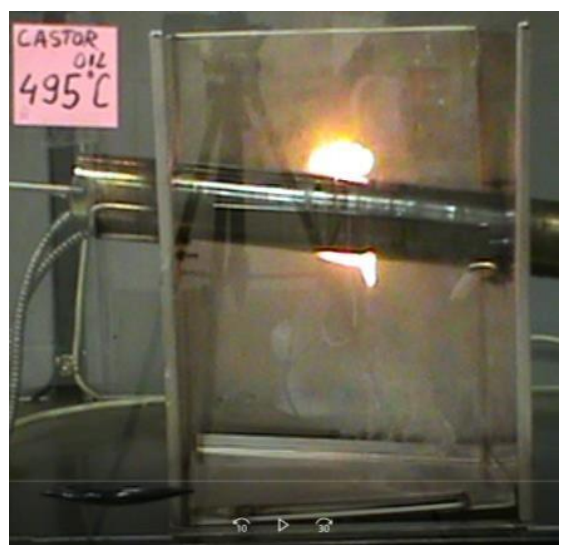

a) $3^{\text {rd }}$ second

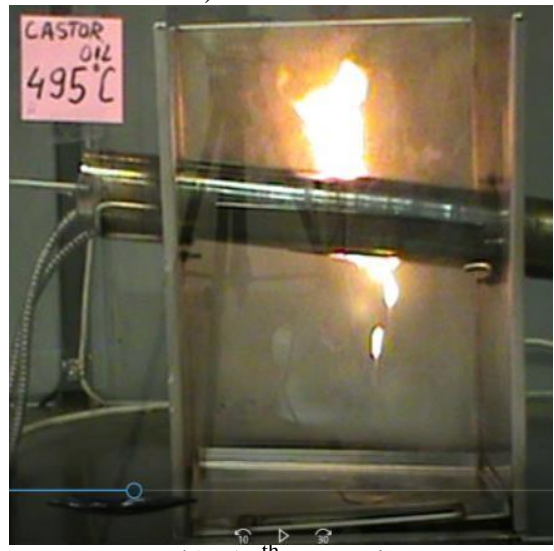

b) $19^{\text {th }}$ second

Fig. 8. Castor oil tested at $495{ }^{\circ} \mathrm{C}$

In the first test the oil ignited after the end of the test period, in the second test the oil burned after the first three seconds from the start of the test (Fig. 8a and $b$ ).

In the next three tests, the oil does not ignite during the test or after the test time has elapsed.

To ensure the maximum temperature at which the castor oil does not ignite, three additional tests were performed at $490{ }^{\circ} \mathrm{C}$ increasing the test time, from 55 to 120 seconds, the flow of dripping oil remaining the same.

Performing these tests it was found that the oil did not ignite (Fig. 9a and b). 


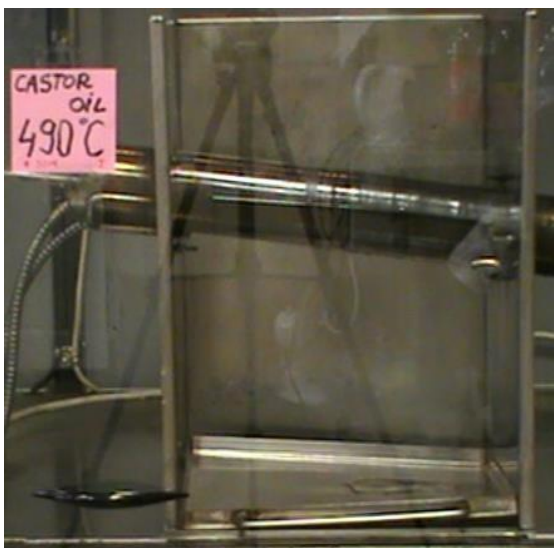

a) Test 1 , after 120 seconds

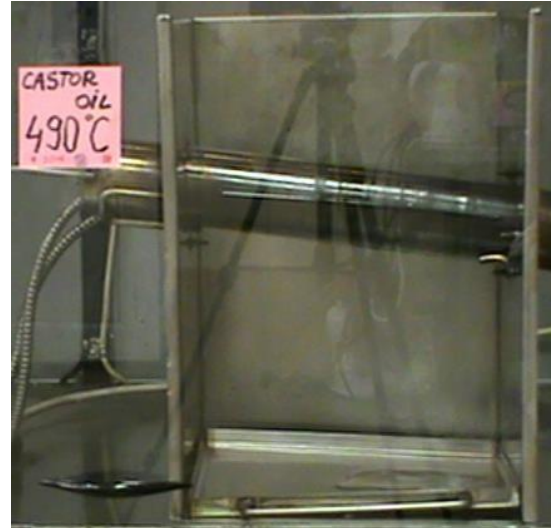

b) Test 3 , afer 120 seconds

Fig. 9. Castor oil tested at $490{ }^{\circ} \mathrm{C}$

The results and the order in which all 29 tests were performed are shown in figure 10.

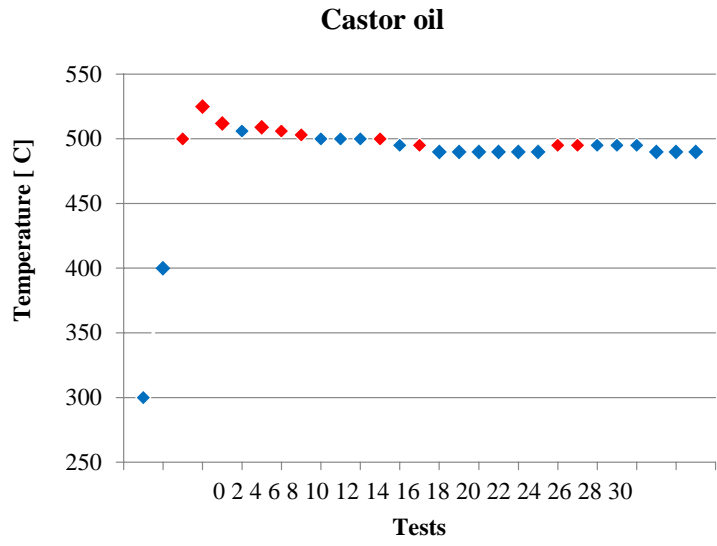

Fig. 9. Castor oil tests (red color - it ignites; blue color - it does not ignite)

\section{CONCLUSIONS}

In order to establish as accurately as possible the flammability temperature on the hot surface of castor oil, a total of 29 tests were performed.

Following the tests performed, it was established that:

- the maximum temperature at which castor oil does not ignite on a hot surface is $490{ }^{\circ} \mathrm{C}$;

- the minimum temperature at which castor oil ignites on a hot surface is $495^{\circ} \mathrm{C}$.
In the case of some tests performed at temperatures of $500{ }^{\circ} \mathrm{C}$ and $495{ }^{\circ} \mathrm{C}$ the oil does not ignite during the test period (55 s) But a few seconds after the end of the test time, the oil remaining on the heated cylinder ignites, so these tests have been repeated.

In the case of tests in which the oil was ignited, the ignited oil is extinguished on contact with the surface of the oil collection tray.

At the maximum temperature at which the oil does not ignite $\left(490{ }^{\circ} \mathrm{C}\right)$ a total of nine tests were performed, in none of these tests did the oil ignite.

At the minimum temperature at which the castor oil ignites $\left(495{ }^{\circ} \mathrm{C}\right)$ a total of seven tests were performed, in three tests the castor oil ignited while in the other four tests it did not ignite.

To make sure, the maximum temperature $(490$ $\left.{ }^{\circ} \mathrm{C}\right)$ at which the castor oil does not ignite, three additional tests were performed, increasing the test time from 55 to 110 seconds, the flow of dripping oil remaining the same.

In order to increase the accuracy, in determining the flammability temperature of an oil on hot surface, more than three tests should be performed at the same temperature.

\section{REFERENCES}

[1] Bogatu L., Dragomir R. E. (2016) Influence of Additives on Antiwear and Extreme Pressure Behaviour of the Vegetable Oils, Revista de Chimie, 67(4), pp. 630-633.

[2] Patel V. R., Dumancas G. G., Viswanath L. C., Maples R., Subong B. J. J. (2016) Castor Oil: Properties, Uses, and Optimization of Processing in Parameters in Commercial Production, Lipids Insights, 9, pp. 1-12.

[3] Dunford N. T. (2012) Food and Industrial Bioproducts and Bioprocessing, John Wiley \& Sons.

[4] Berman P, Nizri S., Wiesman Z. (2011) Castor oil biodiesel and its blends as alternative fuel, Biomass Bioenergy, 35(7), pp. 2861-2866.

[5] Yelchuri V., Azmeera T., Karuna M. S. L. (2019) Metathesized castor oil acylated derivatives: lubricants base stocks with low pour points and superior anti-wear properties, SN Applied Sciences, 1:1214, https://doi.org/10.1007/s42452019-1263-0.

[6] Deleanu L., Ciortan S., Georgescu C. (2011) Flammability Tests on Hot Surface for Several Hydraulic Fluids, Tribology in Industry, 33(3), pp. 96-103.

[7] Solea L. C., (2013) Contribution on studying the rheological and tribological behavior of several biodegradable lubricants based on vegetable oils, $\mathrm{PhD}$ thesis, "Dunarea de Jos" University, Galati.

[8] Bongfa B., Atabor P. A., Barnabas A., Adeotic M. O. (2015) Comparison of lubricant properties of castor oil and commercial engine oil, Journal of Tribology, 5, pp. 1-11.

[9] Ionescu T. F., Sorcaru A. A., Guglea D., Cristea G. C., Georgescu C., Deleanu L. (2020) Rapeseed oil additivated with hexagonal boron nitride, INCAS Bulletin, 12(2), pp. 63-72. 